\title{
Echocardiographic, haemodynamic, and angiographic correlations in hypertrophic cardiomyopathy
}

\author{
ROBERT A. CHAHINE, ALBERT E. RAIZNER, TETSUO ISHIMORI, \\ AND ALFREDO C. MONTERO \\ From the Department of Medicine, Baylor College of Medicine and the Section of Cardiology at the \\ Veterans Administration Hospital, Houston, Texas, U.S.A.
}

Attempts to identify a pathognomonic abnormality in 'idiopathic hypertrophic subaortic stenosis' date back to the time of its recognition. We examined the echocardiographic, haemodynamic, and angiographic features of 14 consecutive patients in whom the clinical diagnosis was supported by the presence of both asymmetrical septal hypertrophy and systolic anterior movement of the anterior leaflet of the mitral valve on the echocardiogram, or an intraventricular pressure gradient at rest or with provocation. A gradient was shown in 12 cases $(86 \%)$, the Brockenbrough or postextrasystolic response in $9(64 \%)$, asymmetrical septal hypertrophy in $11(79 \%)$, systolic anterior movement in $7(50 \%)$, and left ventricular cavity obliteration in systole in $12(86 \%)$.

Correlative analysis of these findings showed 8 of the patients with gradients lacking either asymmetrical septal hypertrophy (2) or systolic anterior movement (5), or both (1). All these had evidence of cavity obliteration. Two additional patients with cavity obliteration had both asymmetrical septal hypertrophy and systolic anterior movement but no gradient, while 2 other patients with gradients showed no evidence of cavity obliteration. The Brockenbrough response was present in 3 patients without systolic anterior movement, one without asymmetrical septal hypertrophy, and one with neither, and was absent in one with both asymmetrical hypertrophy and systolic anterior movement.

In conclusion, there appears to be no pathognomonic finding in this entity and what is usually diagnosed as idiopathic hypertrophic subaortic stenosis may represent a spectrum of pathology rather than a single well-defined disease.

Since it was first recognised a little less than a quarter of a century ago, the entity known as idiopathic hypertrophic subaortic stenosis (Braunwald et al., 1960), hypertrophic obstructive cardiomyopathy (Cohen et al., 1964), muscular subaortic stenosis (Wigle et al., 1967), asymmetrical septal hypertrophy (Henry et al., 1973a), or hypertrophic cardiomyopathy (Goodwin, 1970) has remained the subject of continuing controversy (Criley et al., 1965; Ross et al., 1966; Henry et al., 1973b; Rossen et al., 1974; Criley et al., 1975; Shah, 1975a). First, hypertension was considered as a possible aetiological factor (Brock, 1957, 1959). The role of hypertension, however, was hurriedly excluded and the syndrome was assumed to be idiopathic (Braunwald et al., 1960). The not infrequent observation that this entity may be associated with Received for publication 17 January 1977 hypertension (Moreyra et al., 1970; Hamby et al., 1971) or valvar aortic stenosis (Parker et al., 1969; Block et al., 1973; Johnson et al., 1975) makes one wonder whether this syndrome may not sometimes occur as a consequence of hypertrophy secondary to pressure overload of the left ventricle. Next, there was the controversy about the mechanism underlying the pressure gradient. Was subaortic obstruction clearly responsible (Ross et al., 1966) or could left ventricular cavity obliteration account for the gradient (Criley et al., 1965)? This controversy was further complicated by the additional concept of catheter entrapment (Wigle et al., 1967) as a potential cause of raised intraventricular pressure and an artefactual gradient. Recently, echocardiography has opened up newer horizons in the diagnosis of this disease. The observation of systolic anterior movement of the anterior leaflet of the mitral valve 
toward the septum (Popp and Harrison, 1969; Shah et al., 1969) and the demonstration of asymmetrical septal hypertrophy (Abbasi et al., 1972; Henry et al., 1973a) seemed to establish firm grounds for the localisation of the obstruction. The impressive finding of asymmetrical septal hypertrophy in this entity led to its acceptance as the pathognomonic anatomical abnormality in idiopathic hypertrophic subaortic stenosis (Henry et al., 1973a). However, cases of idiopathic hypertrophic subaortic stenosis with symmetrical left ventricular hypertrophy were described (Rossen et al., 1974) and asymmetrical septal hypertrophy was found in patients without idiopathic hypertrophic subaortic stenosis (Feizi and Emanuel, 1975; Larter et al., 1976). Further, systolic anterior movement has been reported in conditions other than idiopathic hypertrophic subaortic stenosis and cases without systolic anterior movement have been described (Criley et al., 1976).

In an attempt to assess the relative incidence of the characteristic features of idiopathic hypertrophic subaortic stenosis and determine whether any of them is truly pathognomonic, we undertook a careful and complete echocardiographic, haemodynamic, and angiographic study of all patients presenting with a clinical picture suggestive of this syndrome. Our findings in those in whom the diagnosis was confirmed by echocardiographic or haemodynamic criteria constitute the subject of this report.

\section{Subjects and methods}

All symptomatic patients who presented with the clinical features of idiopathic hypertrophic subaortic stenosis were subjected to careful and complete echocardiographic, haemodynamic, and angiographic study. Patients were diagnosed as idiopathic hypertrophic subaortic stenosis and included in this study if they had (a) clinical features of idiopathic hypertrophic subaortic stenosis and (b) echocardiographic or haemodynamic observations confirming the diagnosis.

Three or more of the following clinical features were required: (1) a history of angina, dyspnoea, dizziness, or syncope; (2) rapidly rising bisferiens carotid pulse; (3) an apical impulse displaying 'triple ripple' or double systolic impulse on the apex cardiogram; (4) a systolic murmur at the left sternal border, increasing with standing, the Valsalva manoeuvre, or administration of amyl nitrite, and decreasing with squatting or in the supine position; (5) evidence of left ventricular hypertrophy on physical examination, on the electrocardiogram, or on the chest $x$-ray film.
Patients presenting with these features qualified for a final diagnosis of idiopathic hypertrophic subaortic stenosis and inclusion in this study only if the clinical picture was supplemented by demonstration at cardiac catheterisation of an intraventricular pressure gradient at rest or with provocation; or by demonstration of asymmetrical septal hypertrophy and systolic anterior movement of the anterior leaflet of the mitral valve by echocardiography.

The echocardiograms were obtained in the supine or left oblique position using a Smith-Kline Ekoline-20A Diagnostic Ultrasonoscope and $2 \cdot 25$ $\mathrm{MHz} \mathrm{Cl2}$, focused transducer with a repetition rate of 1000 impulses per second. The output of the ultrasonoscope was recorded on a Honeywell Strip Chart Fiberoptic Recorder at a paper speed of 20 and $50 \mathrm{~mm}$ per second with a simultaneously recorded electrocardiogram. Special efforts were made in each case to obtain adequate visualisation of the interventricular septum, the left ventricular posterior wall, and both leaflets of the mitral valve. Wherever appropriate, the echocardiographic study was repeated after administration of amyl nitrite.

The haemodynamic study consisted of complete right and left heart catheterisation. Simultaneous pressures were recorded from the aorta (through a catheter introduced percutaneously via the femoral artery) and at various levels in the left ventricular cavity (through a catheter introduced via a brachial arteriotomy). The pressures were recorded at rest, after a premature ventricular contraction, and during at least one of the following interventions: administration of amyl nitrite, intravenous infusion of isoprenaline, or the Valsalva manoeuvre. A slow withdrawal recording of pressure from the left ventricular apex to the aortic root was obtained in most cases.

The angiographic study comprised left ventriculography in the right and left anterior oblique projections and complete selective coronary arteriography.

Only patients with good quality data from all three laboratory sources and satisfying the clinical and laboratory criteria for a final diagnosis of idiopathic hypertrophic subaortic stenosis were included in this study.

\section{Results}

CLINICAL FINDINGS

There were 14 patients who met our selection criteria. Their ages ranged from 27 to 63 years (mean 48). The dominant presenting symptoms were dyspnoea and chest pain and both were des- 
cribed by 11 of the 14 patients ( $79 \%)$. Of the remaining 3 patients, 1 presented with angina without shortness of breath, 1 had dyspnoea but no chest pain, and the third gave history of dizziness and syncope only. Five patients $(36 \%)$ had a history of dizziness but only 3 had documented syncopal episodes. Six patients $(43 \%)$ had a history of hypertension.

On physical examination, all patients were found to have a systolic murmur which was assessed as grade $4 / 6$ in one patient, grade $3 / 6$ in 3 patients, grade $2 / 6$ in 9 , and grade $1 / 6$ in 1 . In all except 2 of these, the murmur increased with standing, the Valsalva manoeuvre, or administration of amyl nitrite, and decreased with squatting. Thirteen patients $(93 \%)$ had an atrial gallop.
The electrocardiogram showed left ventricular hypertrophy with ST-T abnormalities in 8 patients $(57 \%)$. Three patients had electrocardiograms which were within normal limits, 2 had nonspecific ST-T changes, and 1 had large septal Q-waves. Chest $x$-ray films showed cardiomegaly (cardiothoracic ratio more than $50 \%$ ) with prominence of the left ventricle in 4 patients $(29 \%)$; and the heart size was at the upper limit of normal or within normal limits in the remaining 10 patients.

\section{ECHOCARDIOGRAPHIC, HAEMODYNAMIC, AND} ANGIOGRAPHIC FINDINGS

The salient echocardiographic, haemodynamic, and angiographic findings in these 14 patients are shown in the Table.

Table Echocardiographic, haemodymanic, and angiographic findings

\begin{tabular}{|c|c|c|c|c|c|c|c|c|c|c|}
\hline \multirow[b]{2}{*}{ Case No. } & \multicolumn{2}{|c|}{ Echocardiographic observations } & \multicolumn{5}{|c|}{ Haemodynamic observations } & \multicolumn{3}{|c|}{ Angiography } \\
\hline & $I V S / L V P W$ & $S A M$ & $\begin{array}{l}\text { Gradient } \\
\text { Rest }\end{array}$ & $\begin{array}{l}\text { After } \\
\text { provocation }\end{array}$ & $\begin{array}{l}\text { Brockenbrough } \\
\text { response }\end{array}$ & $\begin{array}{l}\text { LVEDP } \\
\text { Rest }\end{array}$ & Stress & $\mathrm{CO}$ & $M R$ & $C A D$ \\
\hline 1 & 1.9 & Yes & 20 & 110 & + & 9 & 24 & No & No & No \\
\hline 2 & $1 \cdot 7$ & No & 23 & 122 & - & 12 & 21 & No & No & No \\
\hline 3 & $1 \cdot 8$ & Yes & 13 & 135 & + & 10 & 10 & PVC & No & Yes \\
\hline 4 & $1 \cdot 8$ & Yes $\star$ & 0 & 150 & + & 6 & 12 & PVC & No & Yes \\
\hline 5 & 1.5 & Yes & 0 & 0 & + & 27 & 27 & PVC & No & No \\
\hline 6 & 1.4 & Yes & 0 & 0 & - & 10 & 10 & Yes & No & No \\
\hline 7 & $1 \cdot 1$ & Yes & 30 & 95 & + & 14 & 17 & Yes & Yes & No \\
\hline 8 & 1.0 & Yes & 10 & 25 & - & 9 & 25 & Yes & No & No \\
\hline 9 & $1 \cdot 2$ & No & 0 & 45 & + & 4 & 11 & Yes & No & No \\
\hline 10 & 1.8 & No & 27 & 103 & + & 11 & 22 & Yes & Yes & No \\
\hline 11 & $1 \cdot 3$ & No & 0 & 35 & + & 13 & 18 & Yes & No & Yes \\
\hline 12 & $1 \cdot 3$ & No & 10 & 30 & + & 23 & 25 & Yes & Yes & No \\
\hline 13 & 1.4 & No & 0 & 40 & - & 6 & 22 & Yes & No & No \\
\hline 14 & 1.5 & No & 0 & 75 & - & 10 & 19 & Yes & No & Yes \\
\hline
\end{tabular}

IVS, interventricular septum; LVPW, left ventricular posterior wall; SAM, systolic anterior movement of anterior leaflet of mitral valve; LVEDP, left ventricular end-diastolic pressure; CO, cavity obliteration; MR, mitral regurgitation; CAD, coronary artery disease ; , SAM occurred only with amyl nitrite; PVC, cavity obliteration occurred only with premature ventricular contractions.

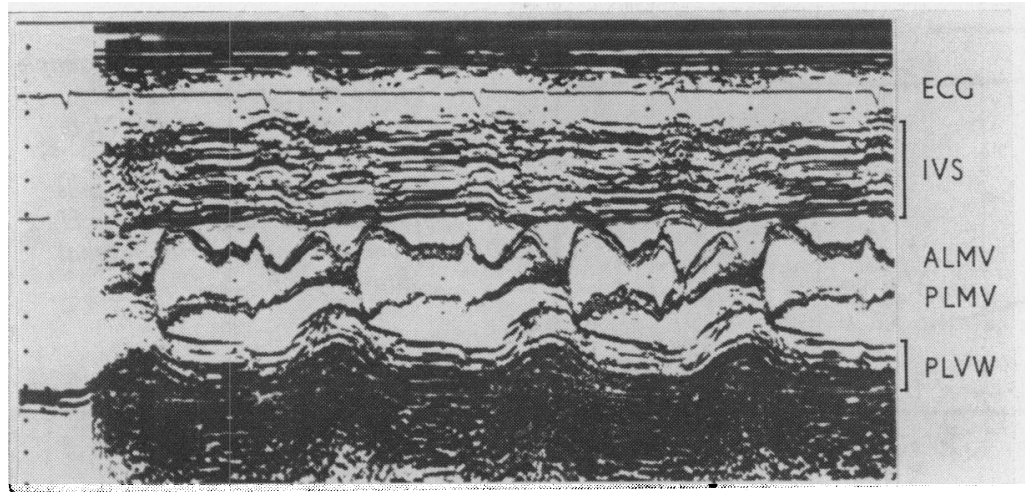

Fig. 1 A representative echocardiogram (not retouched) from one of the patients with the classical echocardiographic findings of idiopathic hypertrophic subaortic stenosis. Note the disproportionately hypertrophied septum (IVS) compared with the left ventricular posterior wall $(P L V W)$ and the typical systolic anterior movement of the anterior leaflet of the mitral valve ( $A L M V)$. 
(A) ECHOCARDIOGRAPHIC DATA

The interventricular septal thickness ranged from 1.3 to $2.8 \mathrm{~cm}$ (mean $1.9 \mathrm{~cm}$ ) and left ventricular posterior wall thickness ranged from 1.0 to $1.7 \mathrm{~cm}$ (mean $1.3 \mathrm{~cm}$ ). The ratio of septal to left ventricular posterior wall thickness (IVS/LVPW) ranged between 1.0 and 1.9 (mean 1.5). Considering a ratio of 1.3 or more as indicative of asymmetrical septal hypertrophy, 11 of the $14(79 \%)$ qualified (Fig. 1). The remaining 3 patients had ratios of $1 \cdot 2$, $1 \cdot 1$, and 1.0 (Fig. 2). Of the 14 patients, $6(43 \%)$ had systolic anterior movement of the anterior leaflet of mitral valve at rest. An additional patient developed systolic anterior movement only with amyl nitrite. Another 2 patients showed convexity of the mitral valve echo in systole but no definite systolic anterior movement. The remaining 5 patients had normal motion of the anterior leaflet of the mitral valve in systole. These patients failed to show systolic anterior movement even with amyl nitrite.

\section{(B) HAEMODYNAMIC FINDINGS}

Seven patients $(50 \%)$ had resting intraventricular gradients ranging between 10 and $30 \mathrm{mmHg}$. All these gradients increased significantly with provocation (after a premature ventricular contraction, the Valsalva manoeuvre, administration of amyl nitrite and/or isoprenaline) (Fig. 3). Gradients thus provoked ranged between 25 and $150 \mathrm{mmHg}$. Five patients $(36 \%)$ who had no resting intraventricular gradient had gradients ranging between 35 and $150 \mathrm{mmHg}$ with provocation. The remaining 2 patients who presented with the typical clinical and echocardiographic features of idiopathic hypertrophic subaortic stenosis had no intraventricular gradients either at rest or with provocation. The Brockenbrough phenomenon was clearly seen in 9

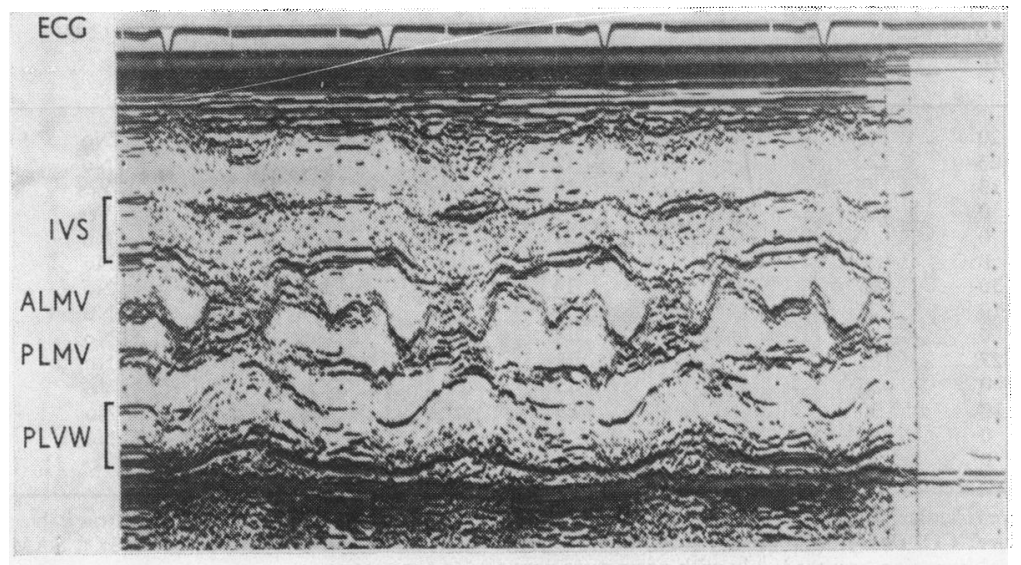

Fig. 2 Echocardiogram (not retouched) from one of the patients without asymmetrical septal hypertrophy. The thickness of the septum (IVS) is about equal to that of the left ventricular posterior wall (PLVW). Systolic anterior movement of the anterior leaflet of the mitral valve ( $A L M V$ ) is present.

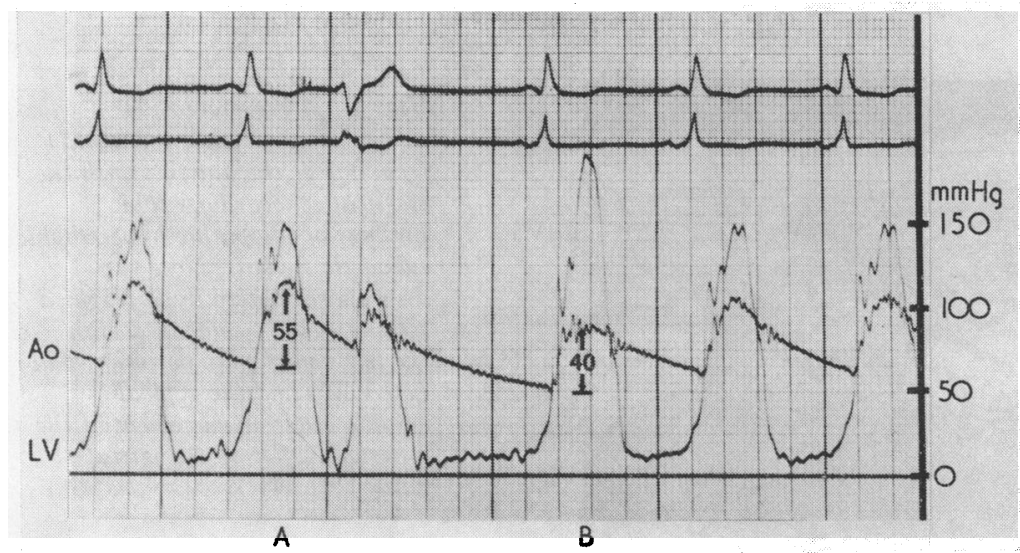

Fig. 3 A representative example of the postextrasystolic or Brockenbrough response. Note that in beat $(B)$, the postextrasystolic beat, the pulse pressure decreased to $40 \mathrm{mmHg}$ from $55 \mathrm{mmHg}$ during normal sinus rhythm $(A)$. 
patients $(64 \%)$ (Fig. 3). The left ventricular enddiastolic pressure was abnormal at rest (more than $12 \mathrm{mmHg}$ ) in only 4 patients $(29 \%)$, but 6 additional patients $(43 \%)$ had abnormal left ventricular end-diastolic pressures of more than $18 \mathrm{mmHg}$ after left ventriculography.

(c) ANGIOGRAPHIC FINDINGS

(1) Left ventriculography

Left ventriculography showed that all patients had large prominent papillary muscles. Nine patients $(64 \%)$ showed left ventricular cavity obliteration during a normal sinus beat and an additional 3 showed cavity obliteration only after premature ventricular contractions (Fig. 4). Mitral regurgitation was seen in only 3 patients $(21 \%)$.

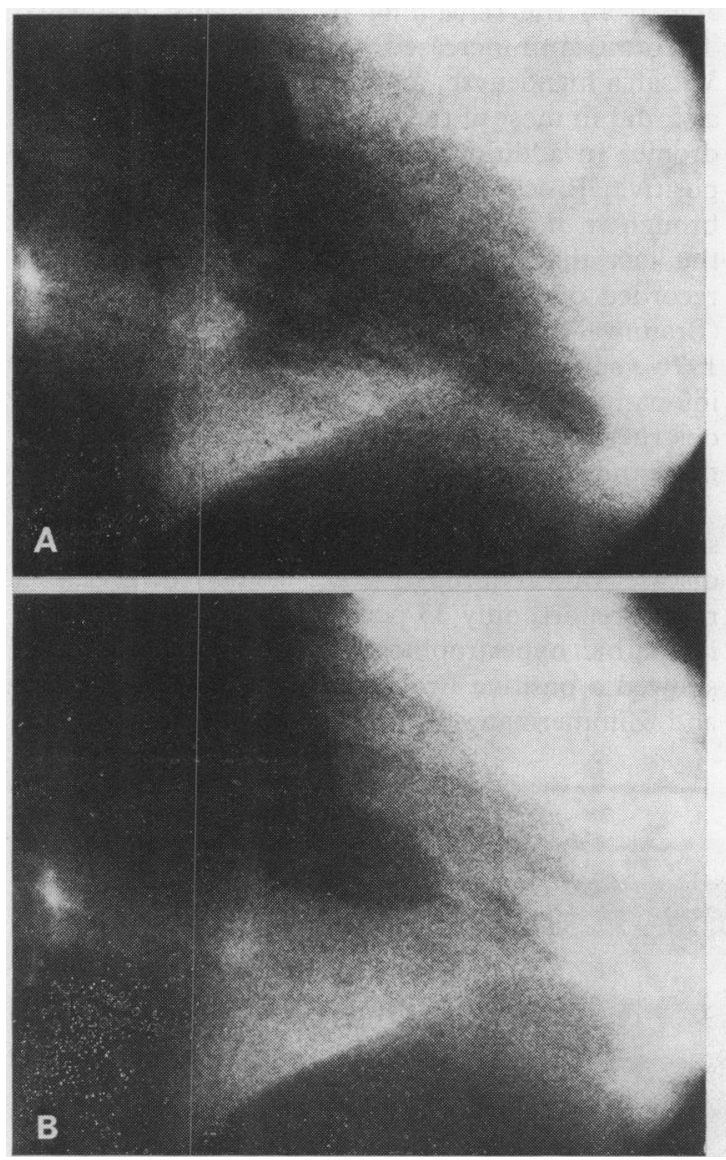

Fig. 4 A representative left ventriculogram illustrating the phenomenon of left ventricular cavity obliteration. Note the normal size of the left ventricular cavity in diastole $(A)$ and the total obliteration of its mid and apical segments in systole $(B)$.

\section{(2) Coronary arteriography}

Ten patients $(71 \%)$ had angiographically normal coronary arteries and 4 patients $(29 \%)$ had evidence of significant coronary artery disease resulting in a decrease of 50 per cent or more in lumen diameter in at least one major coronary artery.

\section{Discussion}

Despite intense interest and a very large number of studies in which attempts have been made to define this entity and establish appropriate diagnostic criteria, idiopathic hypertrophic subaortic stenosis remains an enigma to many interested investigators. Since it was first recognised in 1957 (Brock, 1957), this entity has received more than a dozen names (Criley et al., 1976) and we may still be far from seeing any agreement on a single term (Shah, 1975b).

Many questions remain unanswered: (1) Is this entity always idiopathic or can it sometimes be secondary to pressure overload? (2) Is the gradient when present always secondary to outflow tract obstruction or can it sometimes be the result of cavity obliteration? (3) Hypertrophic cardiomyopathy with 'obstruction' (i.e. with intraventricular gradient) and hypertrophic cardiomyopathy without obstruction: are these different facets of the same disease or two separate diseases? (4) Is the Brockenbrough phenomenon a constant finding? (5) Is asymmetrical septal hypertrophy truly pathognomonic? These are some but not all of the questions that intrigue many researchers who seem fascinated but also sometimes confused by this entity.

It is obviously inconceivable that any one study could answer all these questions. In this study we have tried to examine the frequency of occurrence of commonly accepted characteristic findings as 'diagnostic' criteria for idiopathic hypertrophic subaortic stenosis and to assess whether any of these could be considered truly pathognomonic. The subjects were selected on the basis of a highly suggestive clinical picture (Glick and Braunwald, 1974 ; Ross, 1975) with confirmation of the diagnosis by demonstration of intraventricular pressure gradient at cardiac catheterisation or classical echocardiographic findings, including both asymmetrical septal hypertrophy and systolic anterior movement (Ross, 1975) (Fig. 1).

One of the most important questions regarding the diagnosis of idiopathic hypertrophic subaortic stenosis is whether or not asymmetrical septal hypertrophy may be considered pathognomonic (Henry et al., 1973a). This question can be readily examined in this study. Our data show that asymmetrical septal hypertrophy is a common finding, 
occurring in 79 per cent of our patients. However, 3 of our patients had symmetrical hypertrophy with IVS/LVPW ratio less than 1.3 (Fig. 2). Other cases of idiopathic hypertrophic subaortic stenosis with symmetrical hypertrophy have previously been reported (Epstein et al., 1974; Rossen et al., 1974; Criley et al., 1976). Thus, asymmetrical septal hypertrophy cannot be regarded as pathognomonic. Furthermore, asymmetrical septal hypertrophy has also been described in other conditions, such as persistent ductus arteriosus, ventricular septal defect, myocarditis, aortic stenosis, pulmonary hypertension, and pulmonary stenosis (Feizi and Emanuel, 1975; Larter et al., 1976).

A word of caution is necessary regarding the technical factors that may affect the measurement of the IVS/LVPW ratio. The angulation of the echo beam and the level at which it hits the septum and the left ventricular posterior wall are important considerations (Fig. 5). Measurements should be made at a level at which both mitral valve leaflets are visualised. However, even then the possibility of error cannot be excluded unless an $\mathrm{M}$-mode echocardiographic scan from base to apex is obtained (Fig. 5). An echocardiogram at level A showing fragments of both mitral valve leaflets could have been interpreted as showing symmetrical hypertrophy in a patient with clear asymmetrical septal hypertrophy at levels B and C. Our 3 patients with symmetrical hypertrophy failed to show evidence of asymmetrical septal hypertrophy at any level of the echocardiographic scan.

Our data cast doubt on the commonly accepted belief that an intraventricular gradient can consistently be predicted and quantitatively determined from the echocardiographic recording of asymmetrical septal hypertrophy and systolic anterior movement (Henry et al., 1973c; Epstein et al., 1974). Two patients with asymmetrical septal hyper- trophy and systolic anterior movement showed no gradient either at rest or with provocation, while 3 patients with gradient at rest and 4 with gradient after provocation showed no systolic anterior movement either at rest or with provocation.

An intraventricular pressure gradient is an important feature in patients with idiopathic hypertrophic subaortic stenosis. Those patients with an intraventricular pressure gradient are said to be representative of the 'obstructive' form of the disease, whereas those without it are said to have the 'nonobstructive' form (Goodwin, 1970; Henry et al., 1974). In 12 of the 14 patients in this study an intraventricular pressure gradient was seen at rest or with provocation. The 2 patients in whom no gradient was seen, even with provocation, had both asymmetrical septal hypertrophy and systolic anterior movement and were clinically indistinguishable from the remaining patients with gradients. Their murmur increased with standing and with the Valsalva manoeuvre, and decreased with squatting, as it did in most of the other patients with this syndrome. In addition, one of these 2 patients had a positive Brockenbrough phenomenon (Brockenbrough et al., 1961). These observations, added to the fact that in some patients gradients may be recorded on one occasion but not at a later study (Braunwald et al., 1964; Oakley, 1971; Criley et al., 1976), suggest that the separation of patients with idiopathic hypertrophic subaortic stenosis into obstructive and non-obstructive types may be artificial and unwarranted (Criley et al., 1976).

The Brockenbrough phenomenon has been considered a diagnostic haemodynamic feature of this disease (Brockenbrough et al., 1961). However, in a recent report, only 33 per cent of the patients with idiopathic hypertrophic subaortic stenosis studied showed a positive Brockenbrough response (White and Zimmerman, 1975). In our series, a typical

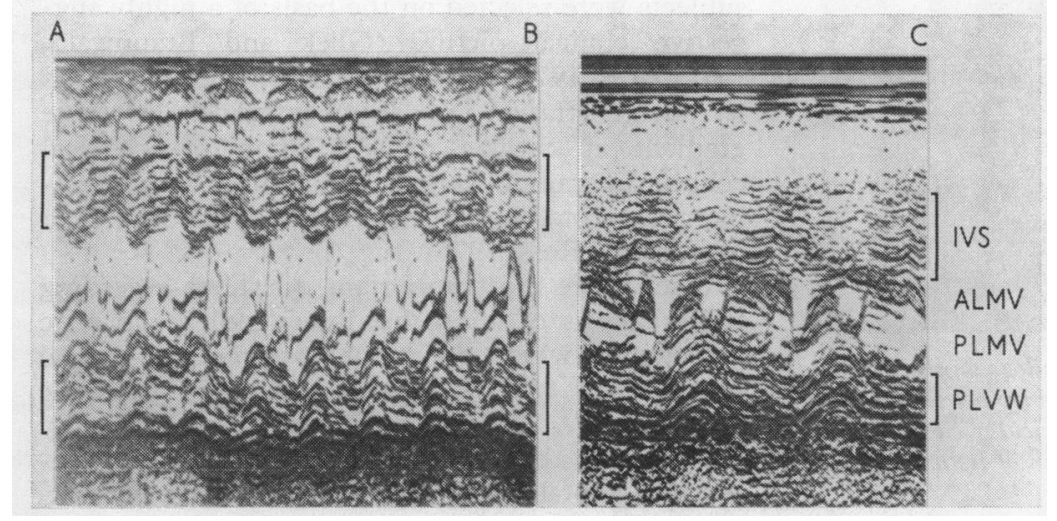

Fig. 5 Echocardiogram (not retouched) showing the classical features of idiopathic hypertrophic subaortic stenosis; asymmetrical septal hypertrophy and systolic anterior movement are seen at levels $B$ and $C$, while at level $A$ the hypertrophy of the septum (IVS) and left ventricular posterior wall (PLVW) appears to be symmetrical. $A L M V=$ anterior leaflet of mitral valve; $P L M V=$ posterior leaflet of mitral valve 
Brockenbrough response (Fig. 3) was clearly demonstrable in 9 patients. In 5, the Brockenbrough phenomenon could not be elicited though 2 had a resting intraventricular pressure gradient and 2 a gradient with provocation; in one instance the absence of a typical Brockenbrough phenomenon could be accounted for by an increased percussion wave, but a Brockenbrough response could be recognised if the tidal wave was considered (Falicov and Wang, 1974; Falicov, 1976) (Fig. 6), while in other instances no Brockenbrough response could be seen at all (Fig. 7). On the other hand, a typical Brockenbrough response was seen in some patients with left ventricular cavity obliteration and no other features of 'idiopathic hypertrophic subaortic stenosis' (Raizner et al., 1976). Therefore, the Brockenbrough phenomenon, though an important feature of idiopathic hypertrophic subaortic stenosis, may not be as sensitive or as specific as originally believed.

The left ventricular end-diastolic pressure was raised at rest or after left ventriculography in 10 of the 14 patients $(71 \%)$. However, this finding is clearly nonspecific and as such could not be used as a distinctive haemodynamic diagnostic feature of this disease.

The angiographic study revealed left ventricular cavity obliteration in systole in 9 of the 14 patients $(64 \%)$. In an additional 3 patients, the cavity of the left ventricle was obliterated only after a premature ventricular contraction. In 2 patients left ventricular cavity obliteration was not seen either during normal sinus beats or with premature ventricular contractions. In these 2 patients gradients cannot be ascribed to cavity obliteration and must be attributed to true obstruction. However, in the 6 patients with cavity obliteration but no systolic anterior motion even with provocation, the possibility that the recorded gradient was the result of the cavity obliteration per se should be considered. An intraventricular pressure gradient secondary to left ventricular cavity obliteration should not be considered artefactual, in contradistinction to that resulting from catheter entrapment between trabeculae of the left ventricular wall. Though the physical mechanism may be similar, in left ventricular cavity obliteration the 'entrapment' is not the result of a technical error, but rather a conse-
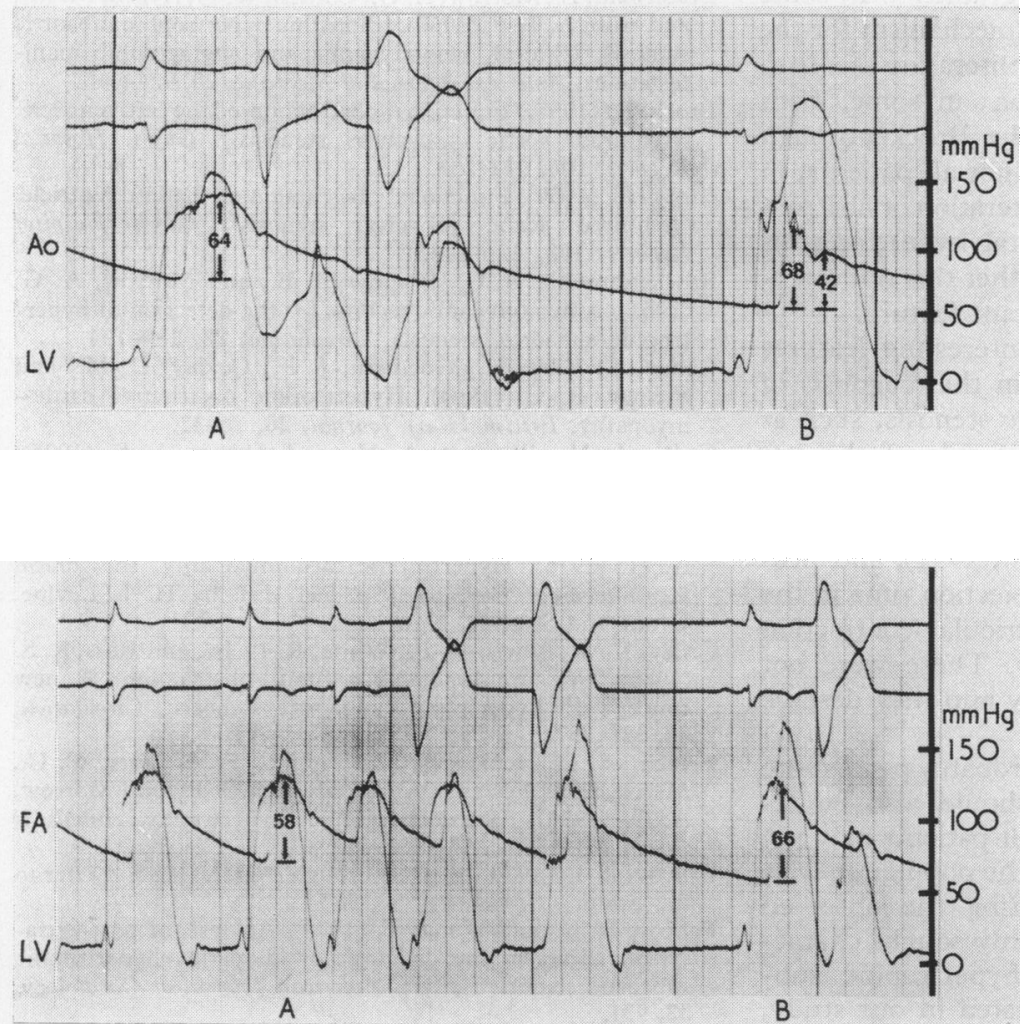

Fig. 6 Left ventricular ( $L V$ ) and aortic pressure (Ao) tracings from a patient in whom a typical Brockenbrough response was absent. Note that in this case the pulse pressure was $68 \mathrm{mmHg}$ in the postextrasystolic beat (B) compared with 64 mmHg in the normal sinus beat (A). However, a Brockenbrough response could be recognised if the tidal wave of beat $(B)$ is considered where the pulse pressure is $42 \mathrm{mmHg}$.

Fig. 7 Left ventricular ( $L V$ ) and femoral artery pressure ( $F A$ ) tracings in a patient with absent Brockenbrough response. Notice that the pulse pressure increased in the postextrasystolic beat (B) to $66 \mathrm{mmHg}$ from $58 \mathrm{mmHg}$ during normal sinus rhythm $(A)$. 
quence of the dynamic contraction that reduces the apical cavity of the left ventricle in systole to an extremely small space. In the 4 cases with an intraventricular pressure gradient, systolic anterior movement, and cavity obliteration, it is not possible to decide whether the gradient is the result of cavity obliteration or obstruction.

All 14 patients in this study had prominent hypertrophied papillary muscles whether or not there was left ventricular cavity obliteration. However, this feature is nonspecific and commonly seen in patients with left ventricular hypertrophy whatever the cause. Of interest also is the low incidence of mitral regurgitation in this series $(21 \%)$. Therefore, it seems unlikely that the murmur of idiopathic hypertrophic subaortic stenosis could be ascribed to mitral regurgitation in a significant proportion of these patients.

In summary, we have a group of patients with idiopathic hypertrophic subaortic stenosis who have many combinations of findings. Intraventricular gradients may occur without the echocardiographic hallmarks of obstruction, asymmetrical septal hypertrophy, or systolic anterior movement of the anterior leaflet of the mitral valve; and the typical echocardiographic findings of obstruction may be present without intraventricular gradients. In some cases, obstruction seems a likely mechanism for the gradient while in others cavity obliteration seems to be a more plausible explanation; in some, both mechanisms may contribute. The Brockenbrough response is present in many but not all patients, in association with either cavity obliteration or obstruction. Though asymmetrical septal hypertrophy is present in the great majority, neither this nor systolic anterior movement is a constant feature.

There are in addition other interesting features which are less commonly used in the diagnosis of idiopathic hypertrophic subaortic stenosis, such as disorientation of the geometrical axis of the left ventricle on ventriculography (Adelman et al., 1969), mid-systolic closure of the aortic valve leaflets on echocardiography (Shah et al., 1971), and prolongation of the left ventricular ejection time in the beat following a premature ventricular contraction (White and Zimmerman, 1975). These were not specifically assessed in this study and may deserve further evaluation.

We recognise that this report probably poses more questions than it answers. It should also be remembered that this series of adult patients may not be perfectly representative of all the population with this disease. However, considering the observed correlations between the commonly sought characteristic features of idiopathic hypertrophic subaortic stenosis which were evaluated in our study, there appears to be no pathognomonic finding; what is usually diagnosed as idiopathic hypertrophic subaortic stenosis may represent a spectrum of pathology rather than a single well-defined disease.

We acknowledge Drs. Henry D. McIntosh and Robert J. Luchi for critical review of this manuscript.

\section{References}

Abbasi, A. S., MacAlpin, R. N., Eber, L. M., and Pearce, M. L. (1972). Echocardiographic diagnosis of idiopathic hypertrophic cardiomyopathy without outflow obstruction. Circulation, 46, 897-904.

Adelman, A. G., McLoughlin, M. J., Marquis, Y., Auger, P., and Wigle, E. D. (1969). Left ventricular cineangiographic observations in muscular subaortic stenosis. American fournal of Cardiology, 24, 689-697.

Block, P. C., Powell, W. J., Jr., Dinsmore, R. E., and Goldblatt, A. (1973). Coexistent fixed congenital and idiopathic hypertrophic subaortic stenosis. American fournal of Cardiology, 31, 523-526.

Braunwald, E., Lambrew, C. T., Rockoff, S. D., Ross, J., and Morrow, A. G. (1964). Idiopathic hypertrophic subaortic stenosis. A description of the disease based upon an analysis of 64 patients. Circulation, 29-30, Suppl. 4, IV 3-119.

Braunwald, E., Morrow, A. G., Cornell, W. P., Aygen, M. M., and Hilbish, T. F. (1960). Idiopathic hypertrophic subaortic stenosis. Clinical, hemodynamic and angiographic manifestations. American fournal of Medicine, 29, 924-945.

Brock, R. (1957). Functional obstruction of the left ventricle. (Acquired aortic subvalvar stenosis.) Guy's Hospital Reports, 106, 221-238.

Brock, R. (1959). Functional obstruction of the left ventricle. (Acquired aortic subvalvar stenosis.) Guy's Hospital Reports, 108, 126-143.

Brockenbrough, E. C., Braunwald, E., and Morrow, A. G. (1961). A hemodynamic technic for the detection of hypertrophic subaortic stenosis. Circulation, 23, 189-194.

Cohen, J., Effat, H., Goodwin, J. F., Oakley, C. M., and Steiner, R. E. (1964). Hypertrophic obstructive cardiomyopathy. British Heart fournal, 26, 16-32.

Criley, J. M., Blaufuss, A. H., and Abbasi, A. S. (1975). Non-obstructive IHSS (Letter to the Editor). Circulation, 52, 963.

Criley, J. M., Lennon, P. A., Abbasi, A. S., and Blaufuss, A. H. (1976). Hypertrophic cardiomyopathy. In Clinical Cardiovascular Physiology, p. 771. Ed. by H. J. Levine. Grune and Stratton, New York.

Criley, J. M., Lewis, K. B., White, R. I., Jr., and Ross, R. S. (1965). Pressure gradients without obstruction. A new concept of 'hypertrophic subaortic stenosis'. Circulation, 32, 881-887.

Epstein, S. E., Henry, W. L., Clark, C. E., Roberts, W. C., Maron, B. J., Ferrans, V. J., Redwood, D. R., and Morrow, A. G. (1974). Asymmetric septal hypertrophy. Annals of Internal Medicine, 81, 650-680.

Falicov, R. E. (1976). Brockenbrough sign in IHSS (Letter to the Editor). Circulation, 53, 584.

Falicov, R. E., and Wang, T. (1974). Analysis of post-extrasystolic beats in the diagnosis of idiopathic hypertrophic subaortic stenosis (letter). American fournal of Cardiology, 33, 931 . 
Feizi, O., and Emanuel, R. (1975). Echocardiographic spectrum of hypertrophic cardiomyopathy. British Heart fournal, 37, 1286-1302.

Glick, G., and Braunwald, E. (1974). Hypertrophic cardiomyopathy. In Harrison's Principles of Internal Medicine, 7th ed., p. 1220 . Ed. by $M$. Wintrobe, G. Thorn, $R$. Adams, E. Braunwald, K. Isselbacher, and R. Petersdorf. McGraw-Hill, New York.

Goodwin, J. F. (1970). Congestive and hypertrophic cardiomyopathies. A decade of study. Lancet, 1, 731-739.

Hamby, R. I., Roberts, G. S., and Meron, J. M. (1971). Hypertension and hypertrophic subaortic stenosis. American fournal of Medicine, 51, 474-481.

Henry, W. L., Clark, C. E., and Epstein, S. E. (1973a). Asymmetric septal hypertrophy. Echocardiographic identification of the pathognomonic anatomic abnormality of IHSS. Circulation, 47, 225-233.

Henry, W. L., Clark, C. E., and Epstein, S. E. (1973b). Asymmetric septal hypertrophy (ASH). The unifying link in the IHHS disease spectrum. Circulation, 47, 827-832.

Henry, W. L., Clark, C. E., Glancy, D. L., and Epstein, S. E. (1973c). Echocardiographic measurement of the left ventricular outflow gradient in idiopathic hypertrophic subaortic stenosis. New England fournal of Medicine, 288, 989-993.

Henry, W. L., Clark, C. E., Roberts, W. C., Morrow, A. G., and Epstein, S. E. (1974). Differences in distribution of myocardial abnormalities in patients with obstructive and nonobstructive asymmetric septal hypertrophy (ASH). Circulation, 50, 447-455.

Johnson, A. D., Lonky, S. A., and Carleton, R. A. (1975). Combined hypertrophic subaortic stenosis and calcific aortic valvular stenosis. American fournal of Cardiology, 35, 706-709.

Larter, W. E., Allen, H. D., Sahn, D. J., and Golberg, S. J. (1976). The asymmetrically hypertrophied septum, further differentiation of its causes. Circulation, 53, 19-27.

Moreyra, E., Knibbe, P., and Brest, A. N. (1970). Hypertension and muscular subaortic stenosis. Chest, 57, 87-90.

Oakley, C. M. (1971). Hypertrophic obstructive cardiomyopathy. Patterns of progression. In Hypertrophic Obstructive Cardiomyopathy, p. 9. Ed. by G. E. W. Wolstenholme and M. O'Connor. J. and A. Churchill, London.

Parker, D. P., Kaplan, M. A., and Connolly, J. E. (1969). Co-existent aortic valvular and functional hypertrophic subaortic stenosis. Clinical, physiologic and angiographic aspects. American fournal of Cardiology, 24, 307-317.
Popp, R. L., and Harrison, D. C. (1969). Ultrasound in the diagnosis and evaluation of therapy of idiopathic hypertrophic subaortic stenosis. Circulation, 40, 905-914.

Raizner, A. E., Chahine, R. A., Ishimori, T., and Awdeh, M. R. (1977). The clinical correlates of left ventricular cavity obliteration. American fournal of Cardiology. (In press.)

Ross, J. (1975). Idiopathic hypertrophic subaortic stenosis. In Textbook of Medicine, 14th ed., p. 973. Ed. by P. B. Beeson and W. McDermott. W. B. Saunders, Philadelphia.

Ross, J., Jr., Braunwald, E., Gault, J. H., Mason, D. T., and Morrow, A. G. (1966). The mechanism of the intraventricular pressure gradient in idiopathic hypertrophic subaortic stenosis. Circulation, 34, 558-578.

Rossen, R. M., Goodman, D. J., Ingham, R. E., and Popp, R. L. (1974). Echocardiographic criteria in the diagnosis of idiopathic hypertrophic subaortic stenosis. Circulation, 50, 747-751.

Shah, P. M. (1975a). Idiopathic hypertrophic subaortic stenosis (hypertrophic obstructive cardiomyopathy). Changing concepts. Chest, 68, 814-817.

Shah, P M. (1975b). IHSS-HOCM-MSS-ASH? Circulation, 51, 577-580.

Shah, P. M., Gramiak, R., Adelman, A. G., and Wigle, E. D. (1971). Role of echocardiography in diagnostic and hemodynamic assessment of hypertrophic subaortic stenosis. Circulation, 44, 891-898.

Shah, P. M., Gramiak, R., and Kramer, D. H. (1969). Ultrasound localization of left ventricular outflow obstruction in hypertrophic obstructive cardiomyopathy. Circulation, 40, 3-11.

White, C. W., and Zimmerman, T. J. (1975). Prolonged left ventricular ejection time in the post-premature beat. A sensitive sign of idiopathic hypertrophic subaortic stenosis. Circulation, 52, 306-312.

Wigle, E. D., Marquis, Y., and Auger, P. (1967). Muscular subaortic stenosis. Initial left ventricular inflow tract pressure in the assessment of intraventricular pressure differences in man. Circulation, 35, 1100-1117.

Requests for reprints to Dr. Robert A. Chahine, Section of Cardiology, Veterans Administration Hospital, 2002 Holcombe Boulevard, Houston, Texas 77211, U.S.A. 